\title{
Sterilization Problem Identified
}

National Cancer Institute

\section{Source}

National Cancer Institute. Sterilization Problem Identified. NCI Thesaurus. Code C139576.

Problems that occurred during terminal sterilization by the manufacturer. 